\title{
Analysis of a Shift in the Business Environment and Post-Covid-19 Consumer Behaviour (A Case Study of Residents in Lagos Nigeria)
}

\author{
Adunchezor, O.R ${ }^{1 *}$, Akenade A.S ${ }^{2}$ \\ ${ }^{1}$ School of Business \& Management, Texila American University, Nicoragua, India \\ ${ }^{2}$ Finance Unit, College of Medicine, University of Lagos, Nigeria
}

\begin{abstract}
With the current global pandemic and the consequent social distancing rule limiting business and market operation, it has propelled a shift in the way businesses and organizations operate from the traditional physical market place to the adoption of information technology for business digitalization. These have also affected the attitudinal aspect of consumers and shoppers, particularly on the prospect of consumers going back to their old habits once the global crisis is over. This study, therefore, examines the conditions for consumer preference of the changing digitalized business environment in the Post-COVID-19 Era and its predictive value in the future. The study adopted a survey research design, using an online questionnaire as a research instrument among residents in Lagos. From the findings of the study, it was revealed that the perceived benefit of business digitalization, combined influence attitudes of consumers behaviour and perceived convenience is the most significant of conditions for the preference of the changing digitalized business environment that affects attitudes of consumers. On the prospect of the digitalized business environment in the postCOVID-19 business environments, the study revealed that a 1 percent change in the conditions for consumer preference of online constructs is likely to have an 8.4 percent effect on consumer's attitudes. This, therefore, is an indication that a 1 percent change can have a significant effect on consumer's buying behaviour. Conclusively the study recommended that online retailers should consider improving their technological infrastructure in order to offer more convenience for Customers online shoppers.
\end{abstract}

Keywords: Business Digitalisation, COVID-19, Consumer habits, Customer experience, Consumer Preference), Pandemic.

\section{Introduction}

Recent Studies have contextualized the factors predicting changes in consumer behaviour into four categories. The first which is related to social influence such as communities, friends and family, life events such as marriage and having off springs. The second $\mathrm{d}$ groups are innovations and development factors that cause a change, the business pressure or upgrades a product which subsequently leads to a break of the old consumer habit. Examples are technological innovations such as smartphones and the internet that introduced e-commerce that has revolutionized the customer shopping experience. The third category factors affecting consumer behaviour are government regulatory policies and laws. According to [1], these factors are often related to public health and shared spaces as well as the consumption of unhealthy products. Public regulations affecting consumer behaviour could be in the form of policies dissuading the consumption of alcohol or cigarette and those that encourage the use of environmentally friendly machinery like electric cars or solar-powered homes. The fourth category is ad hoc natural disasters like 
floods, earthquakes, or global health crisis, including the COVID-19 pandemic outbreak of 2020, which resulted in a major shift in various ways of life, including consumer behaviour and decision making. [2] identified psychological approaches adopted in decision-making, with five major approaches: Economic Man, Psychodynamic, Behaviourist, Cognitive, and Humanistic. Furthermore, [3] showcased that consumer buying decisions indicate how well the company's marketing strategy fits market demand. Thus, marketing begins and ends with the consumer customer playing three distinct roles: user, payer, and buyer. [3] further pointed that consumer behaviour is difficult to predict, even for experts in the field. According to [3], Consumer behaviour involves the psychological processes that consumers go through in recognizing their needs, finding ways to solve these needs, making purchase decisions, interpret information, make plans, and implement these plans, e.g., by engaging in comparison shopping or actually purchasing a product.

In the same vein, there are various factors such as income, demographic, cultural, and social status that influence consumer's choice for purchasing a product. Apart from the above internal factors, which can be recognized as influential to consumer behaviour, several situational contexts can be suggested to affect consumer choices. They are mostly regarded as external factors, which can be in the form of external incentives or uncertainties. According to [4], external uncertainties such as natural disasters, war, economic and financial crisis or global health crisis are likely to cause a behavioural change in consumers. Since business profitability is highly dependent on the prevalent consumer behaviour, this subject has significantly attracted the attention of many researchers in exploring strategies of managing consumer choices and the development of models for predicting consumer behaviour.

Consumer behaviour within a market context is also regarded as the trait, attitude, and preference of a consumer for a product or the individual factors that affect the consumer disposition in a market. Since its outbreak of the novel COVID-19, the virus has rapidly spread across the globe, infecting over 1.2 million individuals in Europe alone [5]. As a response to controlling the spread of the virus, various countries around the world activated a mandatory nation-wide lockdown and selfquarantine, issuing restrictions on the movement of individuals and the introduction of social distancing in public gatherings [6].

In Nigeria, the global COVID-19 pandemic is no doubt having a drastic impact on businesses, both large and small. Since the outbreak of the pandemic in Wuhan, China, in December 2019, many businesses have been forced to close, leading to an unequaled disruption of many business operations and activities in various industry sectors [7]. However, In the wake of the COVID-19 virus, there has been a shift in the way businesses and organizations operate. From closing productions and operations to a drop in consumers' confidence, COVID-19 continues to impact businesses in Nigeria and even threaten their very existence.

With lockdown and social distancing, consumers' choice of the place to purchase goods and services is restricted. This has resulted in location constraints and location shortage. [8] noted that this problem has led to the virtual localization of offices, schools, shopping malls through the internet, giving the consumer more time flexibility as consumers do not have to follow schedules planned for going to work or to school or to shop or to consume. A study conducted by [9] revealed despite the change in the business environment, risk and tradition are major inhibitors of consumers who are of the age range of 20 and 57 from the purchase of products via online platforms even in the pandemic. The study further revealed that individuals who were above the age of 55 years regarded usage, image, and perceived value as major inhibitions of mobile banking. 
Another study examining the new business environment by [10] revealed that there are no major inhibitions to adjusting to the digitalization of business-by-business owners. At the same time, consumers identified tradition, image, and risk as major obstacles of innovation acceptance. Rejecters, on the other hand, have the highest rate of impediments to adjusting to the new business environment of innovation, with risk and tradition being the most influential. The risk associated with finance was identified to have an impact on the way old consumers perceive shopping online [11]. In lieu of this, this research will examine post-COVID-19 consumer behaviour in the current state of the changing business environment in Nigeria.

\section{Research Objective}

1. To assess the conditions for consumer preference of the changing digitalized business environment in the Post COVID-19 Era.

2. To examine the predictive value of business digitalization on consumer behaviour in the post-COVID-19 business environment in Nigeria.

\section{Literature Review}

Even though there are limited studies among consumers behaviour in a crisis, the few similar studies that have them provide some insight into the factors that may influence consumer's behaviour in adjusting to innovations and new business environments. For example, a company in the Eastern region of Europe decided to venture into E-payment because of certain factors such as increasing his market base and its convenience of use. The manager of the company testified that indeed E-payment had enabled them to reach a wider market with much ease whilst reducing costs related to financing a new business environment [12]. In another related study conducted by [13], the socio-economic features of individuals also have an impact on their willingness to adopt an innovation. These features include their age, educational status, income, family size, and religion, amongst others.

A study carried out in Japan showed that old aged people were not willing to use new electronic platforms because they saw no problems with their current systems based on their experience. [14] investigates factors impacting internet buying in three cultures: USA, India, and Jordan tested the impact of consumer characteristics, uncertainty avoidance, and perceived risk on internet buying. The results revealed valuable insights into the nature of internet buying and the factors that limited internet-buying acceptance across cultures and uncovered that in cultures where uncertainty avoidance is high, the perceived risk with the internet buying is also high, and this impacts internet buying negatively. In cultures where the perceived risk is high, it impacts internet buying negatively [14].

Other factors include the availability of resources, available markets, affordability of the new technology, low level of risks associated with the technology, and the benefits they would derive from its usage. Another reason that serves as the basis for online shoppers to opt for a particular technology is their perception about it [15]. Some research studies have also applied the TPB to investigate engagement in using a new business environment. Findings from these studies broadly show that using client engagement is influenced by several factors. For instance, [16] investigated the extent of development and factors that influence the use and satisfaction of electronic payment services in west Africa. They used a sample of 588 participants who were conveniently sampled from the customer base of nineteen banks in Nigeria. They found that perception of security of e-payment, cost of technology, and service reliability significantly influenced customer's willingness to use epayment services.

Interestingly, however, literacy of information technology did not account for 
significant variance in the use of e-payment services. Even though the banks have deployed different e-payment services, a substantial number of the customers $(42 \%)$ indicated that they still preferred the traditional banking methods in addition to e-payments, with $4.8 \%$ indicating that they prefer only traditional banking methods. In similar studies, [17] have reported different factors that pose a challenge to in post-crisis situations. [17] found that factors such as a frequent breakdown of machines, slow process of service delivery, long queues, and inaccessibility of business pose a severe challenge in the post-conflict situation.

A study [18] also researched managerial and usage challenges associated with business digitization using 102 users and five managers of commercial. Their main findings were that they held the view that the complex processes involved in conducting payments posed a challenge to business digitization. Therefore, lack of knowledge 32 and skills in basic computing, lack of trust in non-cash payments, and inadequate marketing (advertisement) campaigns are also challenging to business digitization. The finding of concerning knowledge and skills in basic computing skills hampering business digitalization is contrary to the finding by [19] that literacy in information technology does not account for significant variance in the use of business digitization.

A Study [20] have also reported among bank customers in India that several perceived risk factors act as barriers preventing the customers from using new business services. They found among the customers that most of them still preferred the traditional banking services compared to the technologically oriented mobile banking services. Also, a study by [21] that tested the TPB in predicting the use of internet banking reported that perceived behavioural control and attitude significantly influenced customers' intention to use internet banking. This suggests that attitude towards the behavioural was important in deciding whether to engage in the event of business change. [22], emphasized that implementing new practices requires changes in the behaviour of relevant actors, and this is facilitated by an understanding of the determinants of current and desired behaviours.

\section{The Theory of Planned Behaviour (TPB)}

The Theory of Planned Behaviour (TPB) was developed by [23] to explain people's intention in engaging in a new behaviour in general, not just those that are related to technological adoption. However, because adopting business digitalization constitutes a new behaviour, the TPB is fit to be used as a framework. The TPB was developed from the theory of reasoned action (TRA), which was meant to explain intentions behind engaging in new behaviour rather than the behaviour itself [23]. However, the TRA was found to be limited in predicting actual behaviour, and so the TPB was developed to fill the gaps. The fundamental assumption of the TPB is that for individuals to engage in new behaviour, they must first develop intentions to engage in the behaviour. The theory proposes further that intention is influenced by several psychosocial factors [23]. These factors mainly include risks associated with the behaviour, perceived behavioural control, and subjective norms. Perceived behavioural control is the extent to which individuals believe that they can exercise control over the new behaviour they intend to engage in. Social norms are the pressure that individuals feel within their social environment to engage in the behaviour. Social norms also involve the things individuals hear about technological innovation. In applying the Theory of Planned Behaviour to the current study, for online shoppers in Nigeria to use online shopping behaviours, their intentions to use online shopping have to be there before the adoptions, and use of actual behaviour (i.e., shopping for products online) of using it will follow. The intentions of the consumers to use online shopping will be affected by the different 
kinds of risks that they associate with online shopping. Therefore, in order to understand online shopping behaviours among online shoppers in Nigeria, it is imperative to assess all these elements of risks they associate with online shopping. It is also imperative to assess how things individuals hear about online shopping influence their online shopping behaviour. In this study, electronic word of mouth is examined within the context of what individuals hear about online shopping. [24] buttressed this on how personality and social psychology and unique features of reasons contribute in decision making.

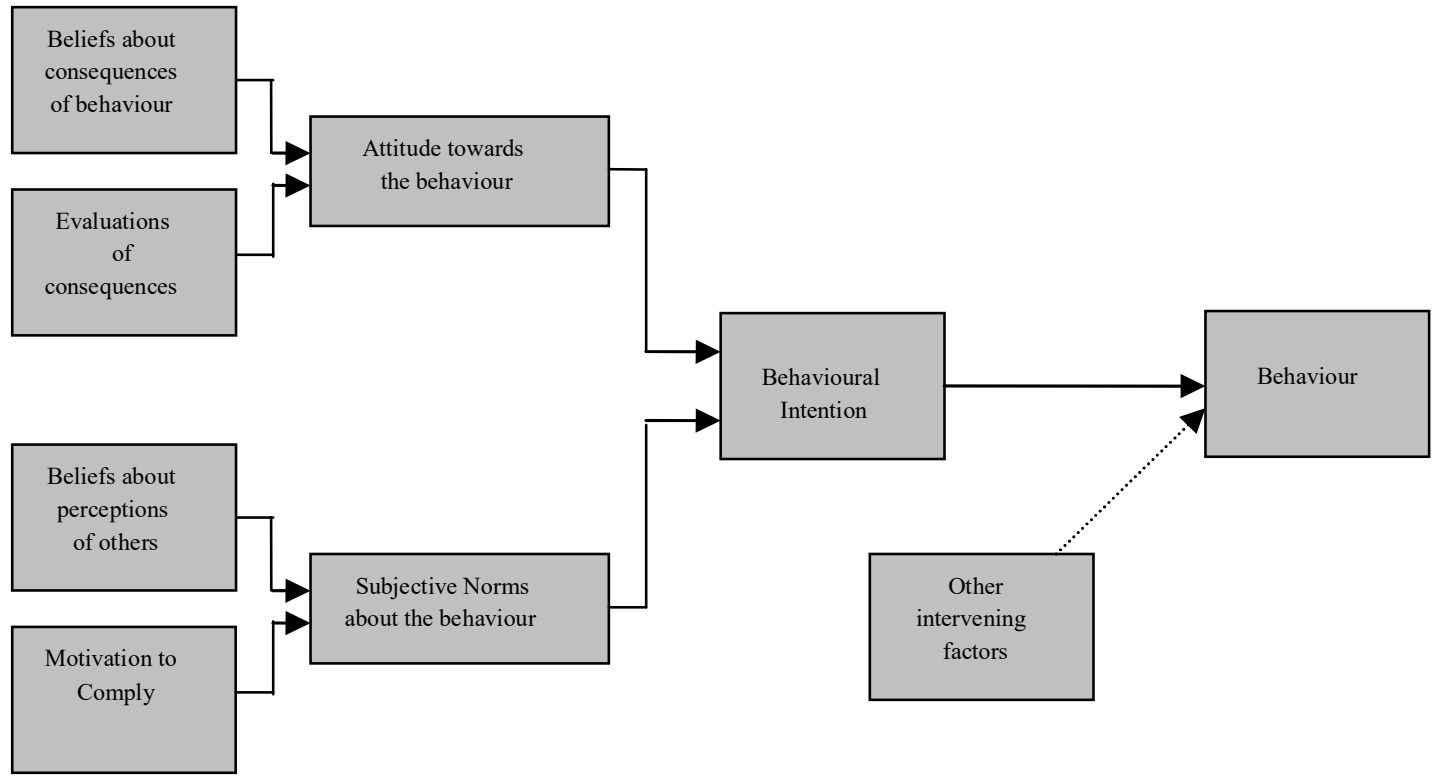

Figure 1. Theory of Reasoned Action

Source: Jeffery P. Bray 2008

\section{Research Methodology}

The study adopted a survey research design, using an online questionnaire as a research instrument among residents in Lagos. The study used a combination of a descriptive and qualitative research approach to ascertain business and consumer opinion and confirm secondary information. Primary data was collected with the aid of a structured questionnaire. A total of 106 questionnaires were circulated to retail traders, Major wholesalers, distributors, and household consumers, while 100 was returned with proper responses. A questionnaire according to [25], was used to obtain statistically useful information ensuring appropriate questions, correct ordering of questions, correct scaling. A descriptive survey was used to analyze the changing business environment in the current global health crisis and the possible post-
COVID-19 consumer behaviour in Nigeria. This involves collecting data to provide answers to the research questions of the study. According to [26], the survey systematically asked subjects the same questions about a situation and measure several variables for purposes of gaining insights about previous behaviours, experiences, or characteristics. This design is considered for this study because it investigates both evidence from secondary data and empirical examination of the opinion of consumers and business owners in Lagos, Nigeria. The survey was chosen because it has the additional cost advantage in terms of funds requirements, time, and number as well as the kinds of participants required for successful analysis.

Data was collected from the target populations comprising of the selected business owners and individuals residing in Lagos. The study employed a combination of three non- 
probabilistic sampling methods, namely purposive, convenience, and quota sampling techniques. Purposive sampling was used to select participants who meet the qualifying criteria of possessing the requisite knowledge about the subject under investigation. This was complemented by the convenience sampling technique to engage qualified respondents who are more convenient and more comfortable to access. The data collected is majorly numerical, collected from an online questionnaire sent to the selected respondent via their emails and processed using the Statistical Package for Social Sciences (SPSS) version 26. The software was used to aid the analysis of quantitative data after they are arranged, coded, and edited. Two types of analytical techniques were employed in the analysis of the quantitative data to achieve the stated objectives of the research, and they are the Univariate and Bi-variate analysis with the level of significance at 0.05 .

\section{Results}

Field data from respondents was inputted into SPSS version 22.0. Descriptive analysis was conducted on the demographic profile of respondents who were surveyed. After which, the three objectives of the study were analyzed with the final data comprising 100 valid responses. The perceived conditions for the preference of business digitalization in the post- variables captured are the merits of utilizing online business platforms such as price, convenience, and variety, as well as product selection. The study examined how these perceived benefits influence the attitude of customers and how sustainable this attitude change is. Statistical measures such as Mean, Error mean (ER), and standard deviation (SD) values were employed in this section. These preliminary measures were done to provide an understanding of the specific measurement.

\section{Discussion}

\section{Education Level of Survey Respondents}

Figure 2 below presents the level of education of the respondents who were surveyed for the study. The results for the study show that 39 respondents, representing 39\%, have at least a degree certificate, followed by Postgraduate (21\%), Diploma (21\%). The data collected further shows that majority of youthful Lagos Nigerian women are using technology to transact business. The least education level of respondents was "other certificate qualification". This statistic implies at least all the respondents who were engaged in the study have at least a level of educational qualification. The dispersion of the level of education also represents a fair representation of the various education levels. The figure is presented below.

COVID 19 business environments. The

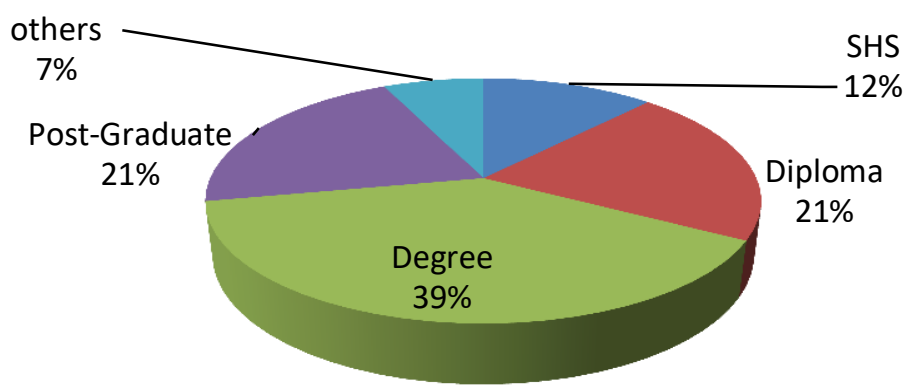

Figure 1. Education Level of Respondents 


\section{Age Ranges of Survey Respondents}

The second demographic profile was the age range of respondents who were surveyed for the study. The study results found that a majority of the respondents, $33 \%$ of respondents, were between 28 to 37 years. This was followed by $20 \%$ of respondents who were within the ages of 48 to 57. It is interesting to note that only 11 respondents out of the 100 were within 58 years or beyond. This shows that the majority of respondents (online shoppers) were young and middle-aged between the ages of 18 and 47 . The Conditions for consumer preference of the changing digitalized business environment.

Results regarding the conditions for consumer preference of business digitalization show an average to even values indicating that all the measures are within a threshold of 1 to 5 (Likert-scale). The results also showed that the most common [specific] conditions for consumer preference of business digitalization influencing attitudes of consumers were, "I like the idea of using the internet to shop," with a mean value of 4.22 and a standard deviation (SD) value of 0.927 . This preliminary finding means that customers perceive that it is a good decision to shop using online platforms. This is very significant because the purpose of online retail technology beyond its COVID 19 social distancing benefits it holds, it is easy and comfortable for consumers or shoppers to purchase online as opposed to visiting the shopping mall for the same goods. This is significant because companies want to ensure that customers can shop without difficulty. This preliminary finding is also relevant in the sense that customers complain of the inconvenience of traveling long distances to purchase goods. Therefore, these findings imply that consumers are "ok" and they like the idea of using online platforms for their shopping. The descriptive analysis further showed that among the [specific] conditions for consumer preference of business digitalization and attitude formation, the least common preference is "I like online shopping because I have a greater variety of products available in every category," where the Mean is 2.66 and SD is 0.094 . This means that online retailers do not offer a variety for online shoppers to choose from. This could be because of the technological nature of the system, where the customer may not be able to see all the categories of products on offer. This is a challenge, and therefore Management of online retail firms must consider providing a wide range of products and service alternatives as well as better services for their consumers.

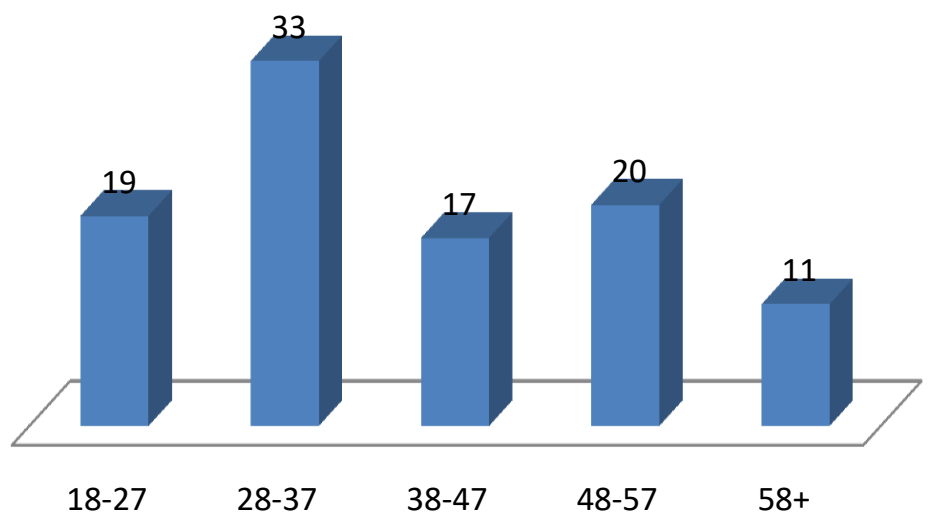

Figure 2. Age Range of Survey Respondents 


\section{Predictive Value of Business Digitalization in the Post-covid-19 Business Environment}

To further examine the predictive value of business digitalization on consumer behaviour in the post COVID-19 business environment, Customer attitude was conceptualized as the dependent variable or outcome variable when the three perceived preferences is favourably considered. Table 1 to 3 presents the hierarchical regression results on the influence of conditions for consumer preference of online shopping on attitude formation of consumers in Lagos, Nigeria. Result is presented below.

The Adjusted R squared (coefficient of determination) of 0.084 in Table 4 indicates that a 1 percent change in the conditions for consumer preference of online constructs is likely to have an 8.4 percent effect on consumer's attitudes. This, therefore, is an indication that a 1 percent change can have a significant effect on consumer's buying behaviour. Based on the result, firms monitor must be interested in perception issues of current and potential online customers next, Table 2 below shows the ANOVA results on whether all [composite] of the three perceived preferences influence attitude formation of current and future consumers.

Table 2 shows the Analysis of Variance [ANOVA] results on how all the conditions for consumer preference of business digitalization influence attitudes. The result demonstrates that "YES", all the three perceived benefits of business digitalization combined influence attitudes of consumers behaviour $(\mathrm{F}=2.965$, $\mathrm{p}=0.036$ ). This finding was arrived at after adding all the three preferences of online shopping (price, variety, and convenience). The next table presents how each of the three perceived preferences individually influences the attitude of online shoppers.

The hierarchical regression results in table 6 show that all the three conditions for the preference of business digitalization significantly influence the attitudes of consumers in Lagos, Nigeria. From the table, there is a significant influence of perceived convenience on attitudes of consumers $(\mathrm{t}=3.887, \beta=0.220 ; \mathrm{p}$-value $=0.000<0.05)$; perceived price and attitudes of consumers $(\mathrm{t}=2.391, \beta=0.140 ; \mathrm{p}$-value $=0.017<0.05)$ and perceived variety and attitudes of consumers $(\mathrm{t}=1.811, \beta=0.105 ; \mathrm{p}$-value $=0.071>0.05) . \mathrm{In}$ effect, the result from the table shows perceived convenience is the most significant of conditions for the preference of the changing digitalized business environment that affect attitudes of consumers followed by variety and price. These findings are consistent with the findings of [14] that revealed price and convenience as key factors that influence the purchase intention of consumers in India.

Table 1. Model Summary: Conditions for Consumer Preference of Online Shopping and Attitudes

\begin{tabular}{|l|l|l|l|l|}
\hline Mode & R R Square & Adjusted R & Std. Error of the I Square & Estimate \\
\hline 1 & $.289^{\mathrm{a}}$ & .084 & .074 & .89154 \\
\hline
\end{tabular}

Predictors: (Constant), Variety, Convenience, Price

Table 2. ANOVA Table: Perceived Preference and Attitudes of Online Shoppers

\begin{tabular}{|l|l|l|l|l|l|}
\hline Model & Sum of Squares & Df & Mean Square & F & Sig. \\
\hline Regression & 7.837 & 3 & 2.612 & 2.965 & $.036^{\mathrm{b}}$ \\
\hline 1 Residual & 84.573 & 96 & .881 & & \\
\hline Total & 92.410 & 99 & & & \\
\hline
\end{tabular}

Dependent Variable: Con Attitude

Predictors: (Constant), Variety, Convenience, Price 
Table 3. Coefficients Table: Perceived Benefit and Attitudes of Online Shoppers

\begin{tabular}{|l|l|l|l|l|l|}
\hline \multirow{2}{*}{ Model } & \multicolumn{2}{|l|}{$\begin{array}{l}\text { Unstandardised } \\
\text { Coefficients }\end{array}$} & $\begin{array}{l}\text { Standardised } \\
\text { Coefficients }\end{array}$ & \multirow{2}{*}{ tig. } \\
\cline { 2 - 5 } & B & Std. Error & Beta & & \\
\hline (Constant) & 2.521 & .304 & .220 & 8.296 & .000 \\
\hline Convenience & .215 & .055 & .140 & 3.887 & .000 \\
\hline Price & .141 & .059 & & 2.391 & .017 \\
\hline Variety & .103 & .057 & .105 & 1.811 & .071 \\
\hline
\end{tabular}

a. Dependent Variable: Con Attitude

Source: Researchers Survey (2020)

\section{Conclusion}

Although several researchers have examined the problem of adjusting to the new internetaided environment, there is little focus on the attitudinal aspect of consumers shoppers, particularly on the prospect of consumers going back to their old habits once the global crisis is over. A shift in the business environment through the digitalization of business has significantly affected consumer attitudes. Thus, a one percent change in the perceived preference of online shopping; perceived price, convenience, and variety increase the chance of positive shopping attitudes by 8.84 percent. Furthermore, the study revealed that there is a significant relationship between perceived convenience in online shopping and the attitudes of consumers in Lagos. A one percent change in perceived preference increases the likelihood of shopping by 22 percent. Also, the findings highlight that there is a significant relationship between perceived price and variety preference in online shopping and attitudes of online shoppers. A one percent change in perceive price leads to a 14 percent chance of positive attitudes of consumers towards online shopping. Finally, in the Lagos, perceived convenience of online shopping was identified as the most important predictor of attitude that consumers exhibit towards online shopping. The study recommends that online retailers should consider improving their technological infrastructure to offer more convenience for Customers online shoppers. The technological infrastructure should be improved to make service delivery flexible, reliable, and cost-efficient. The system should allow current and prospective online shoppers, irrespective of where they are, to easily access relevant information about products, place their order, and know when the product will arrive.

\section{Acknowledgement}

I acknowledge the Texila Faculty, Lecturers and the Texila Journal review team for their mentorship and technical support in making this publication a success. I also thank my co-author and mentor, Dr Akinade S. Adebisi for his mentorship and inputs in making this publication a success.

\section{Disclosure Statement of Possible Conflicts of Interest}

I declare that there is no conflict of interest in the research and publication of this article. 


\section{References}

[1] Kirk, C. P., \& Rifkin, L. S. (2020). I'll Trade You Diamonds for Toilet Paper: Consumer Reacting, Coping and Adapting Behaviors in the COVID-19 Pandemic. Journal of Business Research.

[2] Bray, J. P., 2008. Consumer Behaviour Theory: Approaches and Models. Discussion Paper. Unpublished.

[3] Furaiji, Fatimah and Latuszyńska, Małgorzata and Wawrzyniak, Agata, An Empirical Study of the Factors Influencing Consumer Behaviour in the Electric Appliances Market (2012). Contemporary Economics, Vol. 6, No. 3, pp. 76-86, 2012.

[4] Sheth, J. (2020). Impact of Covid-19 on Consumer Behaviour: Will the Old Habits Return or Die? Journal of Business Research.

[5] 20201005-weekly-epi-update-8.pdf Coronavirus disease (COVID-19): Data as received by WHO from national authorities, as of 04 October 2020, 10 am CEST https://www.who.int/docs/defaultsource/coronaviruse/situation-reports/20201005weekly-epi-update-8.pdf.

[6] Baker, S. R., Farrokhnia, R. A., Meyer, S., Pagel, M., \& Yannelis, C. (2020). How does household spending respond to an epidemic? Consumption during the 2020 COVID-19 pandemic (No. w26949). National Bureau of Economic Research.

[7] Laato, S., Islam, A. N., Farooq, A., \& Dhir, A. (2020). Unusual purchasing behaviour during the early stages of the COVID-19 pandemic: The stimulus-organism-response approach. Journal of Retailing and Consumer Services, 57, 102224.

[8] Stanciu, s., Radu, r. I., Sapira, v., Bratoveanu, b. D. \& Florea, a. M. (2020). Consumer Behaviour in Crisis Situations. Research on the Effects of COVID-19 in Romania. Annals of the University Dunarea de Jos of Galati: Fascicle: I, Economics \& Applied Informatics, 26(1).

[9] Addo, P. C., Jiaming, F., Kulbo, N. B., \& Liangqiang, L. (2020). COVID-19: fear appeal favouring purchase behaviour towards personal protective equipment. The Service Industries Journal, 40(7-8), 471-490.

[10] Ansari, B., \& Ganjoo, M. (2020). Impact of Covid-19 on Advertising: A Perception Study on the
Effects on Print and Broadcast Media and Consumer Behaviour. Purakala with ISSN 0971-2143 is a UGC CARE Journal, 31(28), 52-62.

[11] Choi, T. M. (2020). Innovative "Bring-ServiceNear-Your-Home" Operations under Coronavirus (COVID-19/SARS-CoV-2) Outbreak: Can Logistics Become the Messiah? Transportation Research Part E: Logistics and Transportation Review, 101961.

[12]Richter, C., Kraus, S., Brem, A., Durst, S., \& Giselbrecht, C. (2017). Digital entrepreneurship: Innovative business models for the sharing economy. Creativity and Innovation Management, 26(3), 300-310.

[13]Figiel, S., \& Kufel, J. (2016). Food product innovations and the main consumer trends. Acta Scientiarum Polonorum. Oeconomia, 15(3).

[14]Al Kailani, M., \& Kumar, R. (2011). Investigating Uncertainty Avoidance and Perceived Risk for Impacting.

[15] Branstad, A., \& Solem, B. A. (2020). Emerging theories of consumer-driven market innovation, adoption, and diffusion: A selective review of consumer-oriented studies. Journal of Business Research.

[16] Marotta, G., Nazzaro, C., \& Stanco, M. (2017). How the social responsibility creates value: models of innovation in Italian pasta industry. International Journal of Globalisation and Small Business, 9(2-3), 144-167.

[17] Sakas, D., \& Tomaras, P. (2019). Strategic Innovative Marketing. Springer Proceedings in Business and Economics.

[18] García-Pozo, A., Sánchez-Ollero, J. L., \& OnsCappa, M. (2016). ECO-innovation and economic crisis: a comparative analysis of environmental good practices and labour productivity in the Spanish hotel industry. Journal of cleaner production, 138, 131-138.

[19]Reyes-Mercado, P. (2016). Eco-innovations in emerging markets: Analysing consumer behaviour and adaptability. Springer.

[20] Agwu, M.E and Atuma, Okpara and Ikpefan, Ochei Ailemen and Iyoha, F.O. (2014) Adoption Triggers and Barriers of Mobile Banking Services in Nigeria. International Review of Social Sciences, 2 (9). PP374-386 ISSN2309-0081. 
[21] Arthur, K., Atif, A., Bärnthaler, R., Balcha, W. G., Bellamacina, D., Bocci, M., ... \& MedinaGarcía, C. (2020). Social Innovation in the Face of COVID-19 Pandemic.

[22] Atkins, L., Francis, J., Islam, R. et al. A guide to using the Theoretical Domains Framework of behaviour change to investigate implementation problems. Implementation Sci 12, 77 (2017). https://doi.org/10.1186/s13012-017-0605-9.

[23]Ajzen, I. (2011). The theory of planned behaviour: Reactions and reflections.

[24]Malle, Bertram. (1999). How People Explain Behavior: A New Theoretical Framework.
Personality and social psychology review: an official journal of the Society for Personality and Social Psychology, Inc. $3 . \quad 23-48$. $10.1207 /$ s15327957pspr0301_2.

[25]Roopa, S \& Menta Satya, Rani. (2012). Questionnaire Designing for a Survey. The Journal of Indian Orthodontic Society. 46. 37-41. 10.5005/jp-journals-10021-1104.

[26] Kristayulita, K. (2017). Errors analysis solving problems analogies by Newman procedure using analogical reasoning. International Journal of Humanities and Social Sciences, 9(1), 17-26. 